\title{
ENTRE O HISTORICO E O LITERÁRIO: O SIGNO
}

\author{
Roberto de Oliveira Brandão
}

1. O problema da formação da literatura brasileira além de ser tema inicial obrigatório nos primeiros graus dos nossos cursos de Letras, assume também importância por possibilitar a compreensão de certos aspectos relativos à própria natureza da literatura no seu sentido mais amplo.

$\mathrm{O}$ equacionamento desse problema deve necessariamente levar em consideração três ordens de fatores: históricos, lingüísticos e literários. E preciso acentuar, entretanto, que nenhum desses fatores assume pleno significado independentemente dos outros dois. Formulado em termos de hipótese de trabalho, pedemos dizer que $o$ conceito de literatura brasileira é o resultado sempre precário do lento processo de interação de componentes históricos, lingüísticos e literários.

Observa-se que esse ponto de partida não passa de um momento do processo em curso, já que ele é a transformação (e a superação) de dois postulados básicos, um fornecido pela linguística, outro pela antropologia cultural. O primeiro afirma que o signo lingüístico é arbitrário; o segundo sustenta que não há correspondência necessária entre língua, raça e cultura. Aliás, é exatamente sobre esses dois postulados que repousa a criatividade literária. Sabemos, por exemplo, que na linguagem poética, em seu limite criativo, qualquer vocábulo pode significar qualquer coisa. Sabemos também que na prática cada língua organiza de modo peculiar os dados da experiência. Portanto, a capacidade de nomear novos fatos é consequiência direta da disponibilidade básica que caracteriza os componentes do sistema linguiístico .

Pensados em termos de "formação da literatura brasileira" esses postulados nos levam a propor uma segunda hipótese, como variante da primeira: o conceito de literatura brasileira só pode ser entendido dentro do permanente esforço realizado pela língua portuguesa para expressar a experiência histórica, social, psíquica, literária e lingüistica de seus falantes. 
Esse esforço, entretanto, não se faz de maneira uniforme nem tranquilamente. Por outro lado, as novas formas linguísticas obtidas, resultado de necessidades novas, nem sempre estão prefiguradas nos estágios anteriores, mas, pelo contrário, só podem ser percebidas retrospectivamente. Em termos de criação literária, o futuro virtual só pode ser imaginado através da análise do futuro real limitado pela relação passado/presente.

Isto posto, vejamos um caso concreto ocorrido na literatura brasileira:

2. Trata-se do seguinte soneto de Cláudio Manuel da Costa:

Leia a posteridade, ó pátrio Rio,

Em meus versos teu nome celebrado;

Por que vejas uma hora despertado

$O$ sono vil do esquecimento frio:

Não vês nas tuas margens o sombrio,

Fresco assento de um álamo copado;

Não vês ninfa cantar, pastar o gado

$\mathrm{Na}$ tarde clara do calmoso estio.

Turvo banhando as pálidas areias

Nas porções do riquíssimo tesouro

$O$ vasto campo da ambição recreias.

Que de seus raios o planeta louro

Enriquecendo o influxo em tuas veias,

Quanto em chamas fecunda, brota em ouro.

Em primeiro plano observa-se que o poeta pretende imortalizar com seu canto o rio de sua pátria, como ele explica no "Prólogo" que introduz suas Obras:

“A desconsolação de não poder substabelecer aqui as delícias do Tejo, do Lima e do Mondego, me fez entorpecer o engenho dentro do meu berço; nada bastou para deixar de confessar a seu respeito a maior paixão. Esta me persuadiu a invocar muitas vezes e a escrever a Fábula do Ribeirão do Carmo, rio o mais rico desta Capitania, que corre, e dava o nome à cidade Mariana, minha Pátria, quando era Vila"

Essa passagem nos esclarece a respeito de certas motivações que presidiram à realização do poema. O poeta, tendo vivido em Portugal, lamenta não encontrar aqui aquilo que lá aprendera a valorizar: uma atividade literária intensa e de acordo com os padrões estéticos então aceitos. 
Mas, como declara no "Prólogo" e sugere no poema, uma força maior o liga à terra natal, simbolizada pelo rio, e o obriga a "confessar em meus versos...a maior paixão" Em outros termos, não há coerção estética e de escola capazes de anular inteiramente a sensibilidade do poeta:

1) diante da realidade;

2) diante de suas raizes nacionais;

3) diante da inércia da linguagem que se recusa a acompanhar o dinamismo dos fenômenos.

Entretanto, esse triplo compromisso do poeta, com o real, com o nacional, com a língua, nem sempre representa uma conquista fácil. Note-se que Cláudio resiste em assumir aquelas três funções, pelo menos ao nível da consciência. Ele fala na "desconsolação de não poder substabelecer aqui as delícias do Tejo, do Lima e do Mondego", fato que o levou a "entorpecer o engenho dentro do meu berço" E em outro lugar lamenta: "Não permitiu o Céu que alguns influxos, que devi às águas do Mondego, se prosperassem por muito tempo" E, finalmente, assumindo a crítica de sua atitude poética, lamenta:

$$
\begin{aligned}
& \text { "E infelicidade que haja de confessar que vejo e aprovo o } \\
& \text { melhor, mas sigo o contrário na execução" }
\end{aligned}
$$

Aí chegamos ao ponto chave do problema: o poeta divide-se em dois; um "eu" ao nível da consciência, que se identifica com os valores do colonizador e, portanto, assume os símbolos deste, e outro "eu" que, não tendo ainda organizado um sistema de valores, alimenta-se dos estímulos da realidade, e, com base nela cria um conjunto de imagens, não como distanciamento, mas como presença efetiva. Neste momento a palavra poética recupera sua função original de um "falar natural" que apreende o particular sensível.

Nesse sentido Vico, buscando as origens da poesia, opõe a "metafísica ragionata", que afirma: "homo inteligendo fit omnia", à "metafisica fantastica", que sustenta: "homo non inteligendo fit omnia" $\mathrm{Ou}$, como explica o próprio Vico:

" l'uomo con l'intendere spiega la sua mente e comprende esse cose, ma col non intendere egli di sé fa esse cose e, col transformandovisi, lo diventa" (1).

Portanto, se Cláudio pretende imortalizar o rio e, por extensão, sua pátria, ele só poderá fazê-lo através do ato fundador da palavra original que, ao nomear o ainda não nomeado, o cria. Esse é, na

(1) - La Scienza Nuovo. lib. II, Sez. II, Cap. II. 
verdade, o sentido subjacente da expressão "despertar o sono vil do esquecimento frio", em que se fundem duas imagens: o despertar e o renascer como instâncias superiores, em qualquer de seus níveis, ao sono e à morte.

Mas, como se instalará esse ato criador? No poema em foco, Cláudio parece realizá-lo basicamente de duas maneiras: primeiramente, pelo que poderíamos chamar de imagem da ausência como presença. Ela cobre todo o segundo quarteto. $\mathrm{Na}$ verdade, o poeta apresenta uma imagem inversa, por exemplo, àquela criada por Gonçalves Dias na "Canção do Exílio" Enquanto este encontra-se em Portugal e sente saudades do Brasil, Cláudio está no Brasil e sente nostalgia de Portugal. E, se levarmos um pouco mais longe o paralelo, poderemos dizer que enquanto um cristaliza a imagem da pátria através do processo de afirmação de uma realidade, mesmo reconhecendo que esta foi idealizada:

\section{"Minha terra tem palmeiras \\ Onde canta o sabiá"}

o outro o faz utilizando uma forma negativa:

"Não vês nas tuas margens o sombrio,

Fresco assento de um álamo copado"

Em síntase, do ponto de vista da poética assumida conscientemente, Cláudio tem resistências em ver a realidade brasileira. Ele apenas percebe uma ausência, a da natureza estereotipada do Arcadismo. Por esse motivo não encontra palavras para nomeá-la senão recorrendo às expressões poéticas arcádicas. Dito de outro modo, o poeta não possui uma linguagem adequada para designar o específico da realidade brasileira como imagem poética. Ao consegui-la estaria não apenas possibilitando a existência do real, mas, ao mesmo tempo, criando a sua imagem poética .

Entretanto, não será adequado dizer que o poeta arcádico revela menor amor à pátria do que o romântico, pois ele apenas possui o sentimento, a percepção e a forma expressiva que lhe permite seu momento histórico e literário.

Por outro lado, se o poeta não encontra uma imagem poética da realidade é porque julga que esta não possui qualidades poéticas. Daí ter ele de apreender o real no seu estado bruto enquanto presente não idealizado. E é o que faz Cláudio no primeiro terceto. O rio brasileiro é aí qualificado de turvo, adjetivo que deita raizes em dupla referência: como indicação da realidade e como valor moral. Aliás, no "Prólogo" ele reproduz essa duplicidade: 
"Turva e feia, a corrente destes ribeiros, primeiro que arrebate as idéias de um Poeta, deixa ponderar a ambiciosa fadiga de minerar a terra, que lhe tem pervertido as cores"

Portanto, é turvo o rio porque suas águas são revolvidas pelo ato de minerar o ouro, o que representa um acontecimento nada poético, pois funda-se em um interesse puramente mundano, que é o enriquecimento. Ambos os referentes ancoram o poema de Cláudio na realidade histórica e poética de seu tempo.

A verdade é que se nem o real nem sua expressão lingüística fossem considerados matéria de poesia, não restaria ao poeta outra coisa senão a paralização da fonte criativa numa repetição sem fim. Ou, então, o silêncio. E, evidentemente, à esta última alternativa que se refere o poeta no "Prólogo":

"... destinado a buscar a Pátria, que por espaço de cinco anos havia deixado, aqui, entre a grosseria dos seus gênios, que, menos pudera eu fazer que entregar-me ao ócio, e sepultar-me na ignorância!"

Mas, essa atitude de racionalização não se efetiva na prática, como vimos, e o pota faz o poema, mesmo que não tenha outra matéria senão a realidade, marco zero da criação .

Finalmente, depois de sentida uma ausência (a do modelo poético arcádico cristalizado) e apontada uma presença (a da realidade histórica brasileira), resta ao poeta moldar o poético como expressão que transfigura o real e a sua linguagem, resgatando-os do banal, do utilitário e do inominado. E o que fará Cláudio no último terceto.

Observa-se que a imagem das águas do rio iluminadas pelo "planeta louro" projeta o referente histórico, isto é, o cíclo da mineração, sobre o plano metafórico das sensações estéticas como beleza puramente contemplada. E a única forma de representar essa projeção é encontrar uma imagem capaz de dar conta do duplo significado da luz que, incidindo sobre as águas, faz brotar tanto o ouro no seu sentido próprio de metal precioso (valor utilitário) quanto o dourado das irradiações luminosas (valor estético) Assim escreve ele:

\footnotetext{
"Que de seus raios o planeta louro

Enriquecendo $o$ influxo em tuas veias,

Quanto em chamas fecunda, brota em ouro"
}

Desse modo o poeta concilia a percepção do real, motivo daquilo que ele chama "ambiciosa fadiga de minerar a terra", com o desejo de criar um objeto que não possua outra função que a de despertar o prazer estético desinteressado, independentemente de qualquer plano utilitário, que é a única missão aceita pelo poeta arcádico. 
Observamos, pois, que Cláudio parte de um pressuposto teórico que não admite a realidade como fonte de poesia, mas, por outro lado, ele sente-se ligado afetivamente a esse real (o rio, sua pátria) e seu desejo é tornar o objeto do sentimento capaz também de expressar sentimento. Então ele cria condições para que o real se transforme em objeto poético, única maneira de poder ser aceito. Realizada a representação artística, o que era limitação passa a ser condição do ato criativo, e versos como estes da "Fábula do Ribeirão do Carmo":

"Competir não pretendo

Contigo, ó cristalino

Tejo que mansamente vais correndo"

assumem inesperadamente um sentido duplo: seja como expressão de inferioridade do rio brasileiro (o que corresponde à aceitação da realidade portuguesa como única fonte de poesia) seja como signo da autonomia da realidade brasileira que, na sua transfiguração poética atende às necessidades emotivas de Cláudio. A relação "turvo/cristalino" marca, portanto, a diferença específica entre a tradição da poesia portuguesa que projeta o poético como real, e a emergente poesia brasileira que projeta o real como poético.

\section{BIBLIOGRAFIA}

BENVENISTE, Emile. "Deux modèles linguistiques de la cité" IN Problémes de Linguistique Générale II. Paris, Gallimard, 1974.

CÂNDIDO, Antônio. "No limiar do novo estilo: Cláudio Manuel da Costa" IN Formação da Literatura Brasileira (Momentos Decisivos). $1^{\text {9 }}$ volume, São Paulo, Martins, 1964.

CÂNDIDO, Antônio e CASTELO, J. Aderaldo. Presença da Literatura Brasileira I. Das Origens ao Romantismo. São Paulo, Difusão Européia do Livro, 1973.

CHOMSKY, Noan. "O aspecto criador do uso da linguagem" IN Lingiiistica Cartesiana, São Paulo, Ed. Vozes/Ed. da USP, 1972.

MARTINET, André. Elementos de Lingüistica Geral. Lisboa, Sá da Costa, 1971.

SAPIR, Edwrd. "Língua, Raça e Cultura" e "Língua e Literatura" IN $A$ Linguagem. Introdução ao Estudo da Fala. Rio, Liv. Acadêmia, 1971.

SCHAFF. Adam. "Language et réalité" IN Problemes du Langage. Col. Diogène. Paris, Gallimard, 1966

SILVA RAMOS, Péricles Eugênio da. Poemas de Cláudio Manuel da Costa. São Paulo, Cultrix, 1966.

VICO, Giambatista. La Scienza Nuova. Bari, Laterza, 1974. 